\title{
Real-Time Monitoring of the Vacuum Degree Based on the Partial Discharge and an Insulation Supplement Design for a Distribution Class Vacuum Interrupter
}

\author{
Seungmin Bang (D), Hyun-Woo Lee and Bang-Wook Lee *(D) \\ Department of Electrical and Electronic Engineering, HVDC EPL, Hanyang University, Ansan-si 15588, Korea; \\ chsd13@hanyang.ac.kr (S.B.); hyunwool@hanyang.ac.kr (H.-W.L.) \\ * Correspondence: bangwook@hanyang.ac.kr
}

check for updates

Citation: Bang, S.; Lee, H.-W.; Lee, B.-W. Real-Time Monitoring of the Vacuum Degree Based on the Partial Discharge and an Insulation Supplement Design for a Distribution Class Vacuum Interrupter. Energies 2021, 14, 7891. https://doi.org/ $10.3390 /$ en14237891

Academic Editors: Ferdinanda Ponci and Tseng King Jet

Received: 30 September 2021 Accepted: 20 November 2021 Published: 24 November 2021

Publisher's Note: MDPI stays neutral with regard to jurisdictional claims in published maps and institutional affiliations.

Copyright: (C) 2021 by the authors. Licensee MDPI, Basel, Switzerland. This article is an open access article distributed under the terms and conditions of the Creative Commons Attribution (CC BY) license (https:/ / creativecommons.org/licenses/by/ $4.0 /)$.

\begin{abstract}
The internal pressure of a vacuum interrupter (VI) is increased by arc heat, ceramic cracking, gas leakage, and manufacturing defects. Accordingly, the dielectric strength of VI rapidly decreases. To improve the reliability of power transmission, efficient maintenance through the realtime monitoring of the vacuum degree is essential. However, real-time monitoring of the vacuum degree is difficult, and related research is scarce. Additionally, due to the insulation problems of this technology, there are few commercially available products. Therefore, this paper proposes a method for real-time monitoring of the vacuum degree and an insulation supplement design for a distribution class VI. First, dielectric experiments were conducted to identify the section in which the dielectric strength of the VI rapidly decreased according to the vacuum degree. Second, for real-time monitoring of the VI, several factors were proposed through the partial discharge in the VI, while the capacitance characteristics of the VI were calculated to improve the signal of the internal partial discharge. Finally, to supplement the dielectric problems of the solid insulation high voltage apparatus that occur when real-time monitoring technology is applied, the insulation supplement design was performed through the finite element method (FEM).
\end{abstract}

Keywords: distribution class; dielectric strength; FEM; high-voltage apparatus; insulation design; partial discharge; real-time monitoring; VI; vacuum degree

\section{Introduction}

In the domestic and international electric power market, the research and development of renewable energy and distributed resources are ongoing [1-4]. For developing solid insulation high-voltage apparatus such as the Load Break Switch (LBS), Vacuum Circuit Breaker (VCB), and Recloser, a Vacuum Interrupter (VI) is used instead of Sulfur hexafluoride $\left(\mathrm{SF}_{6}\right)$ gas [5]. Figure 1 shows the application of VI. The VI is installed inside the housing made by epoxy resin of solid insulation apparatus. It maintains a high vacuum degree of up to $10^{-7}$ torr and has excellent insulation performance. Additionally, both fixed and moving contacts are enclosed in the VI, which performs the current interruption by causing the arc discharge to extinguish naturally in the vacuum. The arc discharge is generated upon opening an electrical path between the electrodes [6-8].

The internal pressure of the VI is caused by arc heat, ceramic cracking, gas leakage, and manufacturing defects. The dielectric strength of the VI rapidly decreases, and the partial discharge between the contact and the floating shield occurs. shows the Paschen curve of the gas. Based on prior research [9-11] and in Figure 2, it can be seen that the dielectric strength rapidly decreases at a certain vacuum degree. 


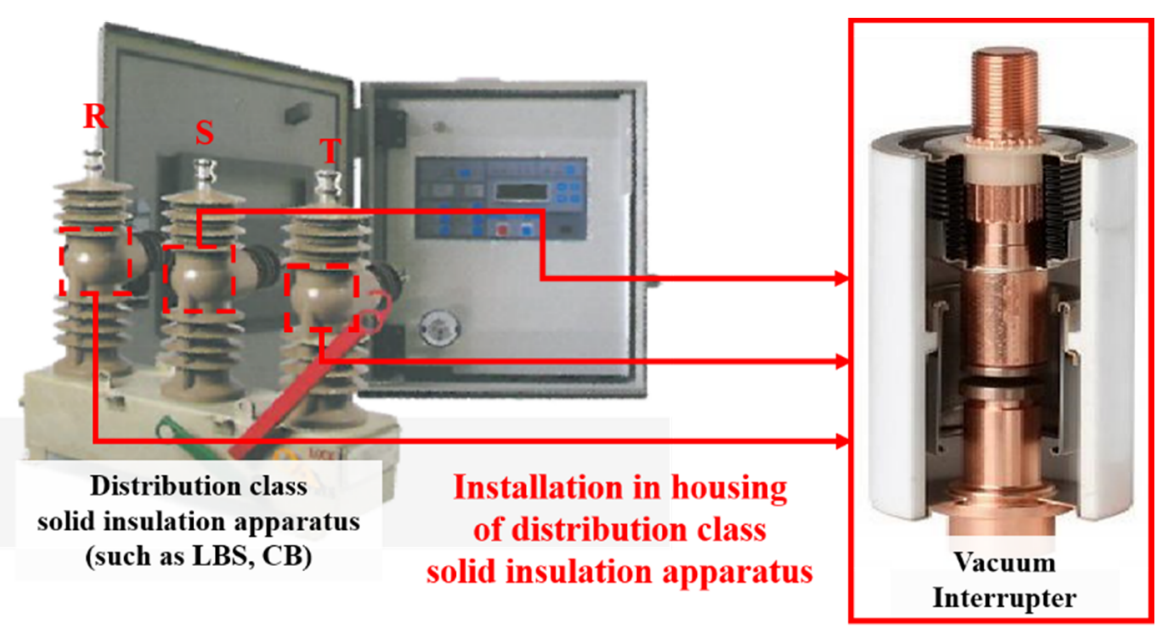

Figure 1. Application of VI.

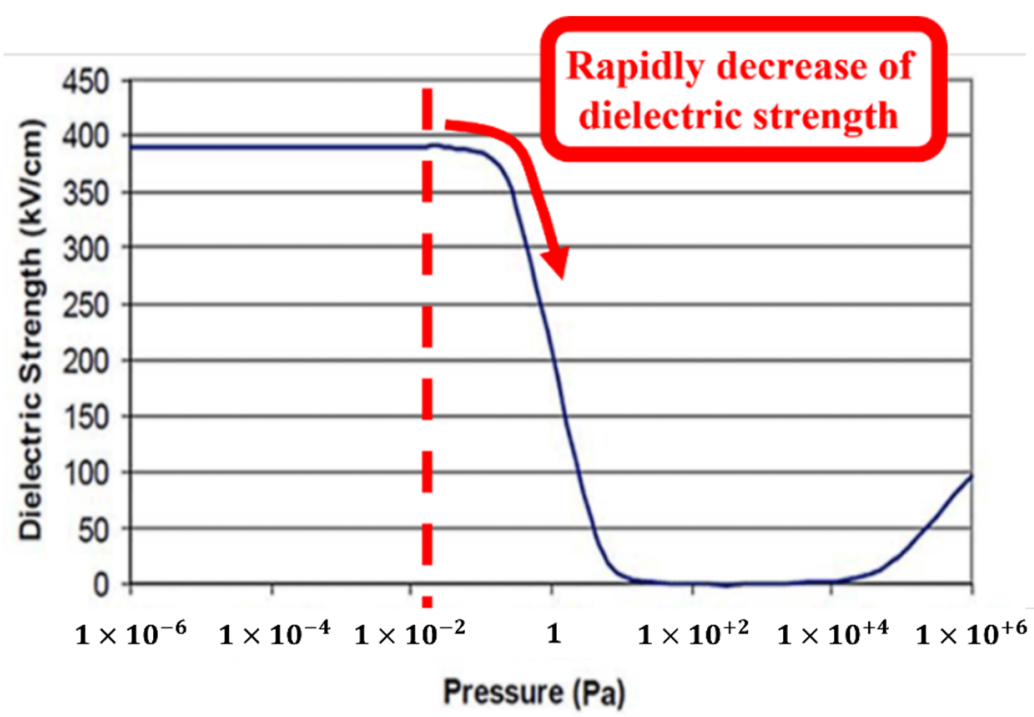

Figure 2. Paschen curve of the gas.

Figure 3 shows that partial discharge occurs in the VI in relation to an increase in the internal pressure. Depending on the vacuum degree, partial discharge occurs between the contact and the floating shield in the closed state and between the contacts in the open state. Resulting dielectric problems cause electrical accidents in solid insulation high voltage apparatus of the VI. To improve the reliability of power transmission, efficient maintenance through real-time monitoring of the vacuum degree of the VI is essential. One of the most significant issues in this process involves the VI installed inside the solid insulation apparatus. In the Republic of Korea, real-time monitoring of VI installed inside a distribution class solid insulation apparatus installed in the transmission system is impossible. Moreover, real-time monitoring of the vacuum degree is difficult, and related research is scarce. Prior to the research carried out in [8-15], only studies on the partial discharge characteristics of the VI according to the vacuum degree were conducted while important factors of real-time monitoring, such as the problem of the trigger value and the duration of the partial discharge signal, were not investigated. 


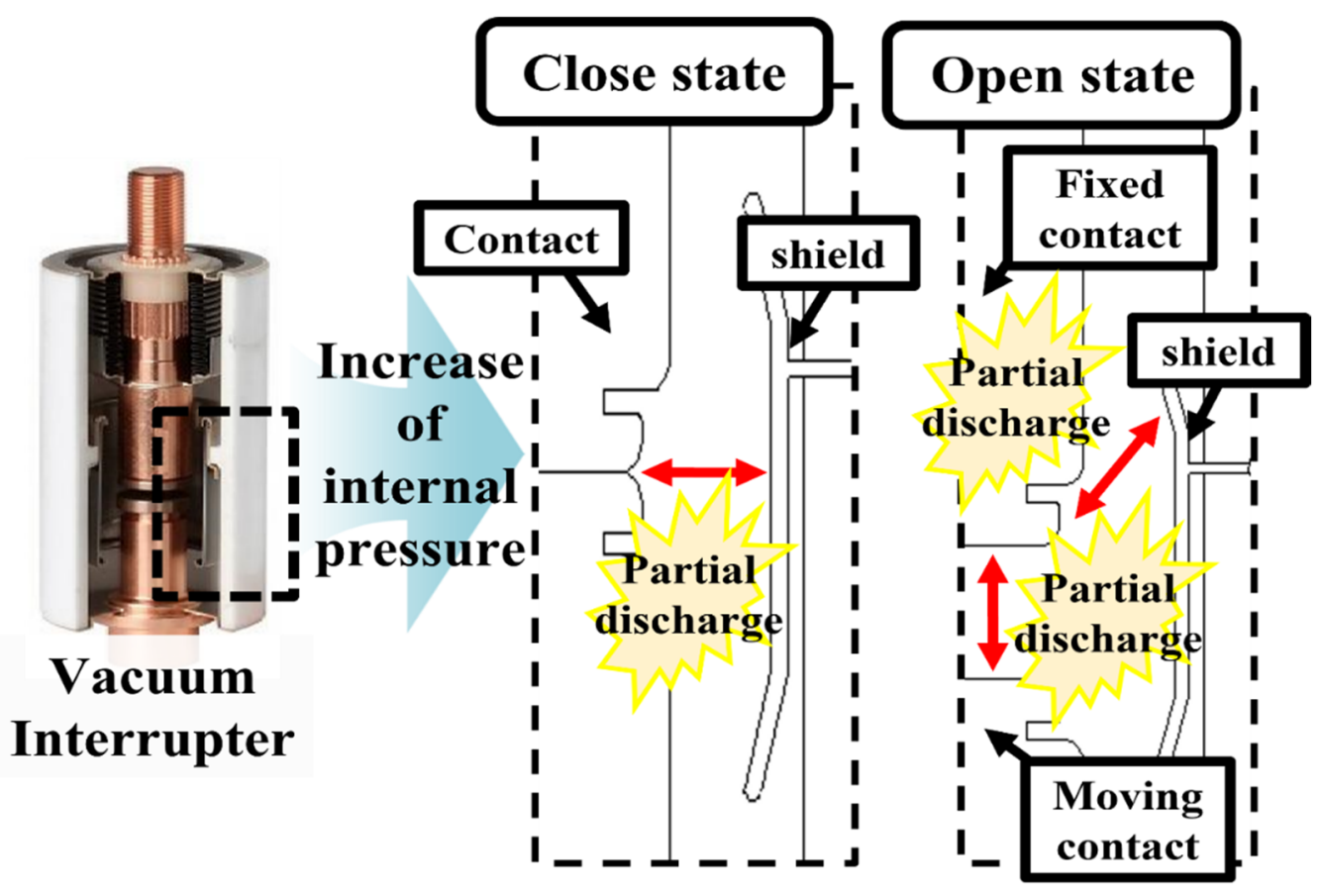

Figure 3. The partial discharge occurred in VI according to the drop of the vacuum degree.

Moreover, the electromagnetic wave, discharge light intensity, and discharge sound as partial discharge characteristics were examined, but the lowest detected pressure is about $1 \mathrm{~Pa}$. The power frequency withstand voltage test is widely adopted by power equipment maintenance personnel in on-site vacuum measuring of VCB [12], but this method cannot give the specific vacuum degree value, only a simple indication of good or bad. Magnetron method also has been adopted by some electric power companies in on-site measurement. Both methods require taking the VCB out of service, and the maintenance is complex [13]. Additionally, only a few products are available commercially because of the insulation problems that occur when this technology is applied, and research into insulation design methods to compensate for these problems has not been conducted. Therefore, in this paper, we propose a method for real-time monitoring of the vacuum degree and an alternative insulation design for a distribution class vacuum interrupter. First, we conducted dielectric experiments to identify the section in which the dielectric strength of the VI rapidly decreased according to the vacuum degree. Second, for real-time monitoring of the VI, monitoring factors were proposed through the partial discharge in the VI. The capacitance characteristics of the VI were calculated to improve the signal of the internal partial discharge. Finally, to supplement the dielectric problems of the solid insulation high-voltage apparatus that occur when real-time monitoring technology is applied, the insulation supplement design was performed through the finite element method (FEM).

\section{Vacuum Holding Experiment and Dielectric Experiment According to the Vacuum Degree in VI}

\subsection{Vacuum Holding Experiment}

In this paper, we studied the development of a real-time monitoring technology on the vacuum degree for distribution class VIs. An experiment is conducted to bring and hold the inside of the VI at a high vacuum state. Figure 4 shows a schematic drawing of the vacuum holding experiment of the VI. To deposit and control the vacuum degree, a combination of a rotary pump with a capacity of $5.0 \times 10^{-2}$ torr and a diffusion pump with a capacity of $1.0 \times 10^{-7}$ torr was used. Further, a vacuum sensor capable of measuring up to $1.0 \times 10^{-7}$ torr was used for real-time monitoring of the vacuum degree. To implement the size of the VI applied to the distribution class apparatus, the size was set to $110 \mathrm{~mm}$ in height and $65 \mathrm{~mm}$ 
in diameter, and the VI was used in the closed state. Figure 5 shows the vacuum holding experiment method; the vacuum degree of the VI is controlled up to $1.0 \times 10^{-6}$ torr using a combination of a rotary pump and a diffusion pump. After that, the power to the pumps is turned off, and the vacuum holding time of the VI is measured while slowly increasing the internal pressure of VI to $1.0 \times 10^{-2}$ torr. A total of 10 experiments were conducted for each set of conditions, and the average holding time was calculated. Table 1 shows the results of the experiment; the " $\mathrm{m}$ " represents the unit of time in minutes, and as can be seen, the vacuum degree of VI can be held for a total of $145 \mathrm{~m}$ from $1.0 \times 10^{-6}$ torr to $1.0 \times 10^{-2}$ torr. Additionally, the vacuum degree is held for the shortest of time at $1.0 \times 10^{-6}$ torr, and it is kept constant at $35 \mathrm{~m}$ intervals from $1.0 \times 10^{-5}$ torr to $1.0 \times 10^{-2}$ torr.

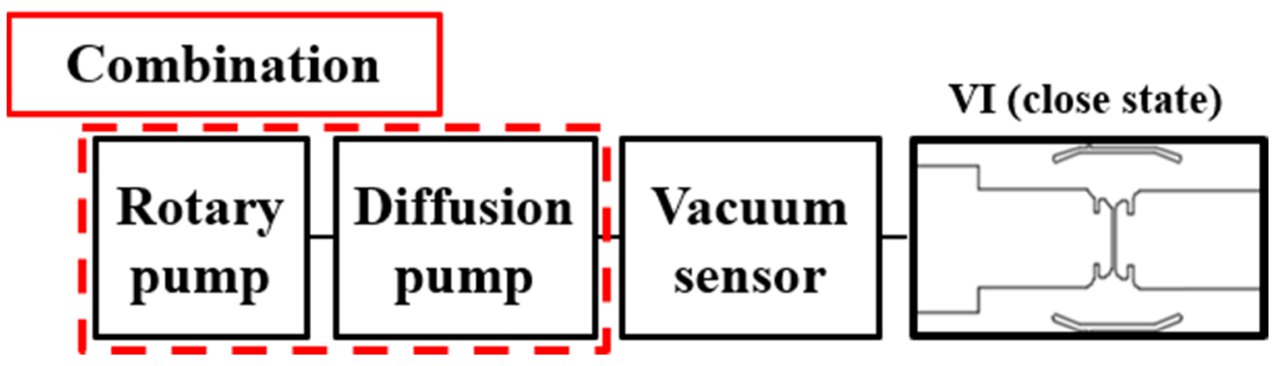

Figure 4. Schematic drawing of vacuum holding experiment of VI.

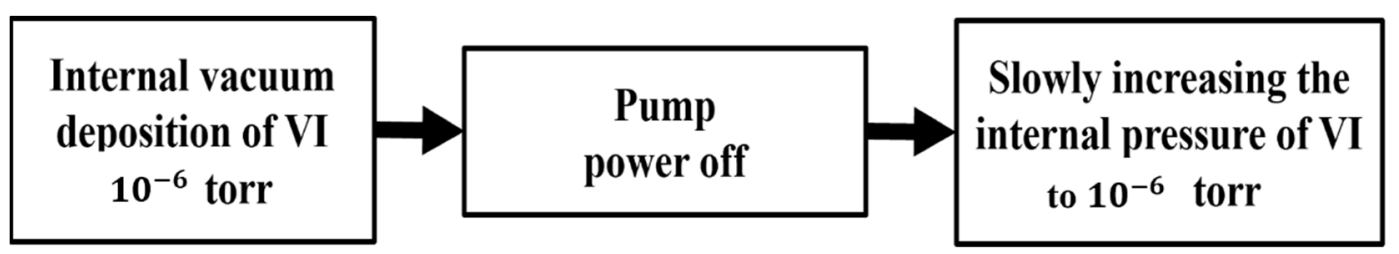

Figure 5. Vacuum holding experiment method of VI.

Table 1. Results of vacuum holding experiment of VI.

\begin{tabular}{ccccccc}
\hline Vacuum Degree & $\mathbf{1 0}^{-\mathbf{6}}$ & $\mathbf{1 0}^{-\mathbf{5}}$ & $\mathbf{1 0}^{-\mathbf{4}}$ & $\mathbf{1 0}^{-\mathbf{3}}$ & $\mathbf{1 0}^{-\mathbf{2}}$ & Total \\
\hline Holding time $(\mathrm{m})$ & 5 & 35 & 35 & 35 & 35 & 145 \\
\hline
\end{tabular}

\subsection{Dielectric Experiment of VI According to Vacuum Degree}

To identify the section in which the dielectric strength of the VI rapidly decreased, dielectric experiments were conducted according to the vacuum degree. As shown in Figure 6, an AC transformer with a capacity of $100 \mathrm{kV}$ (with a cut-off current of $50 \mathrm{~mA}$ ) and a lightning impulse power supply with a capacity of $400 \mathrm{kV}$ and $1.2 \times 50 \mu$ s waveform were used for the dielectric experiment according to the vacuum degree in the VI. As with the vacuum holding experiment, a combination of a rotary pump and a diffusion pump was used to deposit and control the vacuum degree, and a vacuum sensor was used to measure the vacuum degree of the VI. An insulating spacer was installed to impart electrical stability between the vacuum sensor and the VI. The VI was in the open state, and the distance between the contacts was $12 \mathrm{~mm}$. An input voltage was applied to the moving contact of the VI and grounded to the fixed contact of the VI. The vacuum degree of the VI was controlled up to $1.0 \times 10^{-4}$ torr. Subsequently, the power to the pumps was turned off, and dielectric experiments were conducted. 


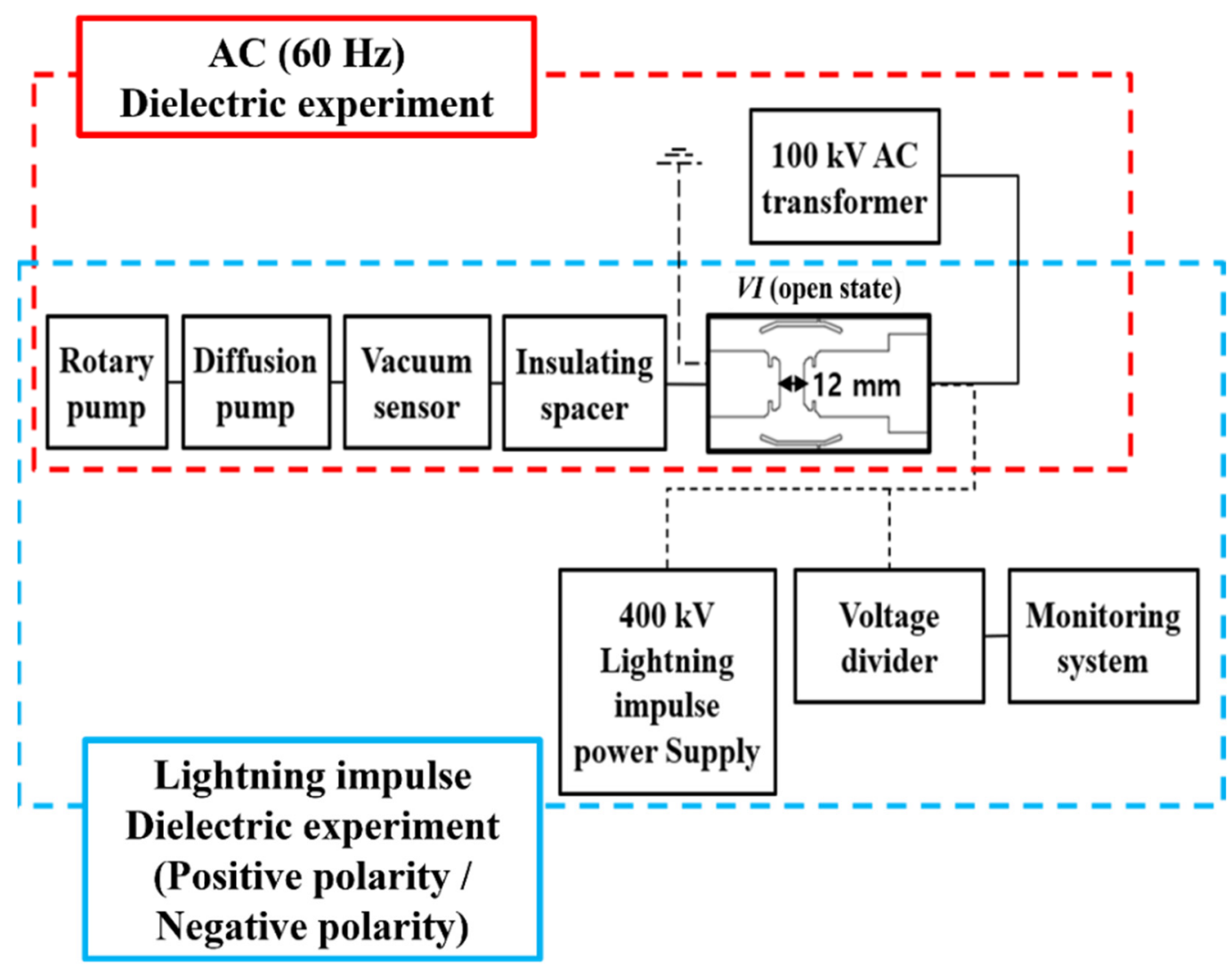

Figure 6. Schematic drawing of AC and lightning impulse experiment of VI according to vacuum degree.

In the case of the dielectric experiment for AC voltage, the AC voltage was raised to $1 \mathrm{kV} / \mathrm{s}$ until dielectric breakdown occurred between the contacts. The dielectric experiment for lightning impulse voltage was conducted until dielectric breakdown occurred between the contacts while increasing by $10 \mathrm{kV}$. At that point, the voltage applied at the time of breakdown was defined as the breakdown voltage. To eliminate the influences of space charge, the time intervals between two successive applied voltages were set to $60 \mathrm{~s}$ and $10 \mathrm{~min}$, respectively. A total of five VIs were used in the dielectric experiment. A total of ten experiments were conducted for each VI, and the average value of eight dielectric breakdown voltage values, excluding the maximum and minimum values, was calculated.

Figure 7 shows the results of the dielectric experiments according to the vacuum degree of the VI, where "negative" and "positive" refer to the negative and positive polarity of the lightning impulse voltage. The red rectangle represents the schematic diagram of the AC dielectric experiment, and the blue rectangle represents the schematic diagram of the lightning impulse dielectric experiment. As the internal pressure of the VI increased from $10^{-4}$ torr to $10^{-1}$ torr, the breakdown voltage decreased. However, as it increased from $10^{-1}$ torr to the atmospheric pressure, the breakdown voltage increased. It is evident that as the dielectric characteristics of a vacuum (such as the Paschen curve of the gas) appeared, the dielectric strength of the vacuum rapidly decreased at $10^{-3}$ torr. Therefore, VI should be replaced when the vacuum degree is about $1 \sim 3 \times 10^{-3}$ torr to ensure high reliability and efficient maintenance. 


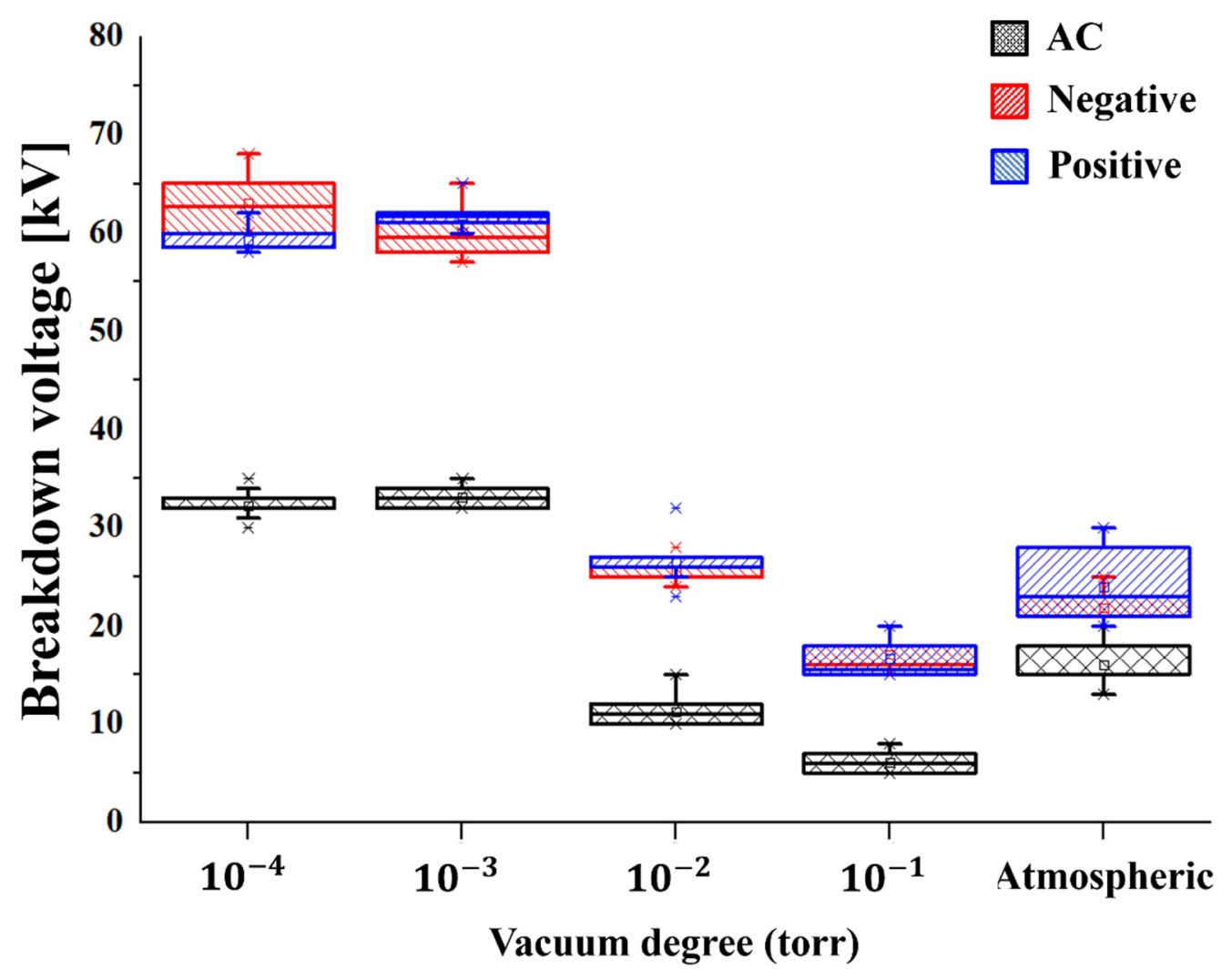

Figure 7. The breakdown voltage of VI according to vacuum degree.

\section{Partial Discharge Experiment of VI According to the Vacuum Degree}

3.1. Capacity Calculation of the Coupling Capacitor

To improve the accuracy of the partial discharge signal, a coupling capacitor was installed when a partial discharge between the contact and floating shield occurred. Figure 8 shows the structure and equivalent circuit when the coupling capacitors were installed in the VI. In Figure $8, V_{0}, V_{a}$, and vs. represent the input voltage between the contact and the ground, the voltage between the contact and the floating shield, and the voltage between the floating shield and the ground, respectively. $C_{a}, C_{s}$, and $C_{c}$ represent the capacitance between the contact and the floating shield, the capacitance between the floating shield and the ground, and the coupling capacitance, respectively. To increase the partial discharge signal between the contact and the floating shield, a coupling capacitor between the floating shield and the ground was installed in the VI. The calculations for before and after the coupling capacitor was installed are expressed by Equations (1) and (2) [16], and the effect of the coupling capacitor represents Figure 9.

$$
\begin{gathered}
V_{a}=\frac{C_{S}}{C_{a}+C_{s}} V_{0}, V_{s}=\frac{C_{a}}{C_{a}+C_{s}} V_{0} \\
V_{a}=\frac{C_{S}+C_{c}}{C_{a}+C_{s}+C_{c}} V_{0}, V_{s}=\frac{C_{a}}{C_{a}+C_{s}+C_{c}} V_{0}
\end{gathered}
$$



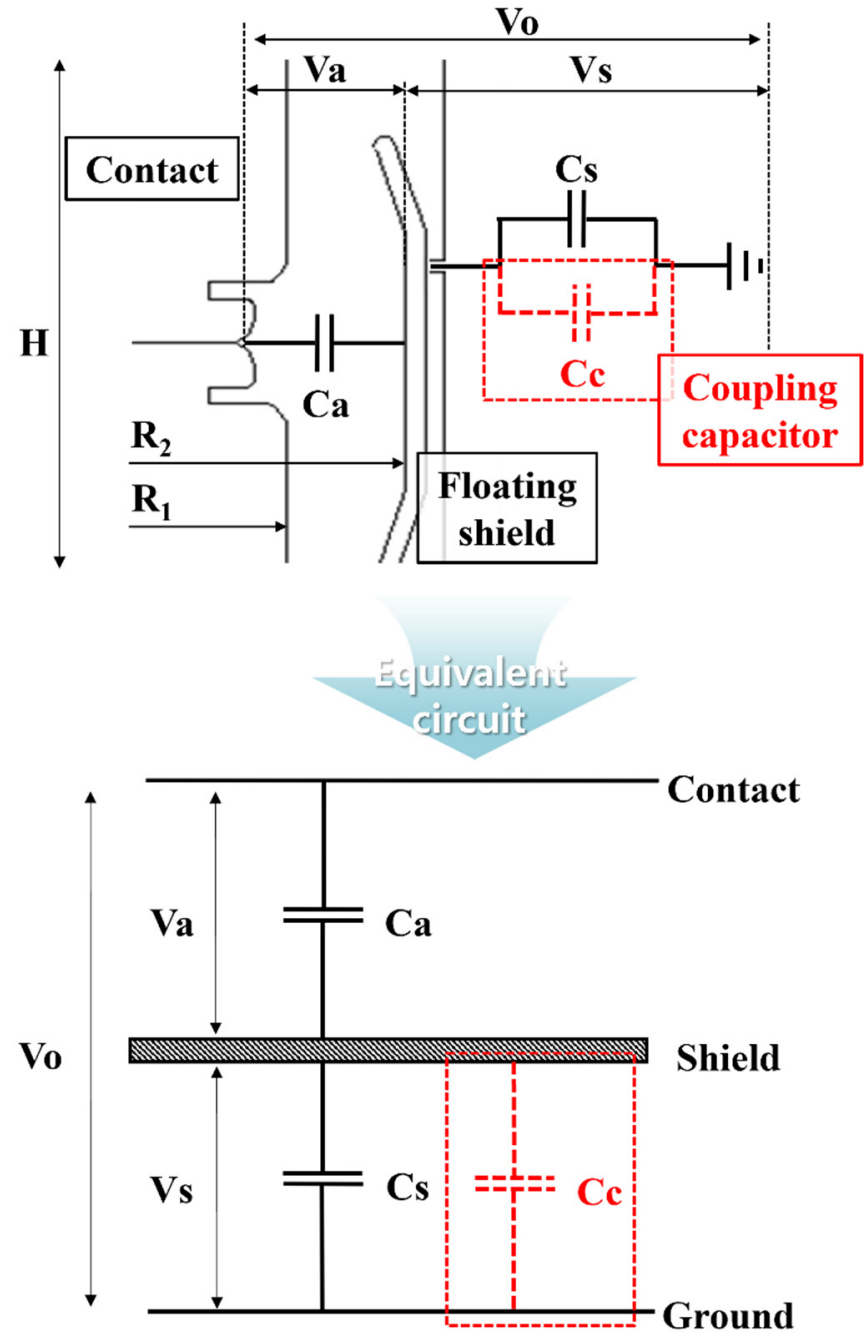

Figure 8. Structure and equivalent circuit when coupling capacitors are installed in VI.

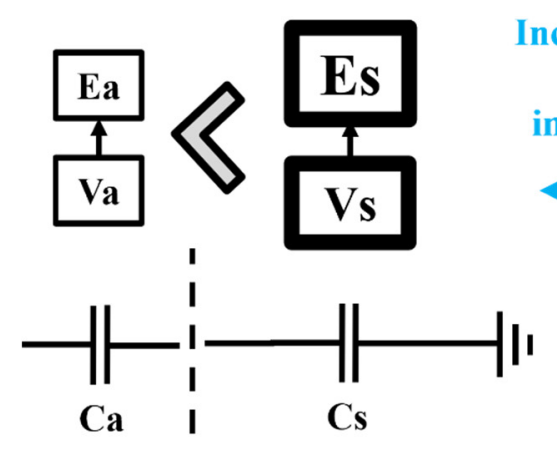

(a)

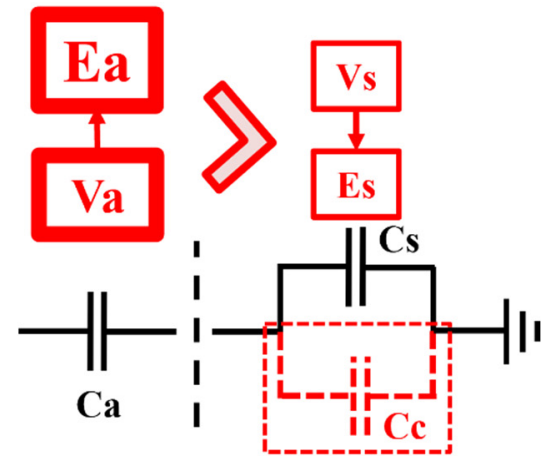

(b)

Figure 9. Effect of the coupling capacitor. (a) before the coupling capacitor was installed; (b)after the coupling capacitor was installed.

As shown in Equations (1), (2), and Figure 9, by installing $C_{c}$ with a larger capacity than $C_{a}$ in parallel with $C_{s}$, the value of $\mathrm{V}_{a}$ increased more than $V_{s}$. When $C_{a}$ was higher than $C_{s}, V_{a}$ was lower than $V_{s}$, and the electric field intensity at $V_{a}\left(E_{a}\right)$ was lower than the electric field intensity at vs. $\left(E_{S}\right)$. If the coupling capacitor is installed in VI, $C_{c}$ is added to $C_{s}$. Therefore, $E_{a}$ is higher than $\mathrm{E}_{\mathrm{s}}$ because $C_{a}$ is lower than $C_{s}+C_{c}$, and the partial 
discharge signals between the contact and the floating shield are larger than the other signals when a partial discharge occurs inside the VI, and the measurement sensitivity can be improved. Therefore, it is important to calculate the capacity of $C_{a}$ to install $C_{c}$ with a larger capacity than $C_{a}$. The Equation for calculating $C_{a}$ is shown below $[17,18]$,

$$
C_{a}=\frac{2 \pi \varepsilon_{0} H}{\ln R_{2} / R_{1}}
$$

In Equation (3), $H$ represents the contact length, $R_{1}$ and $R_{2}$ represent the outside diameter of the contact and the inner diameter of the metal shield, respectively, and $\varepsilon_{0}$ represents the relative permittivity of a vacuum. As a result, the capacitance between the contact and the floating shield of the VI is about $23 \sim 26 \mathrm{pF}$. To analyze the partial discharge characteristics of the VI according to the vacuum degree, a coupling capacitor of $38 \mathrm{pF}$ was installed in the VI.

\subsection{Partial Discharge and Induced Voltage Experiments of VI According to the Vacuum Degree}

In this paper, the partial discharge characteristics occurring between the contact and the floating shield according to the vacuum degree are analyzed. Moreover, the induced voltage characteristics generated through the coupling capacitor are confirmed. Figure 10 shows a schematic drawing of the partial discharge experiment of the VI according to the vacuum degree.

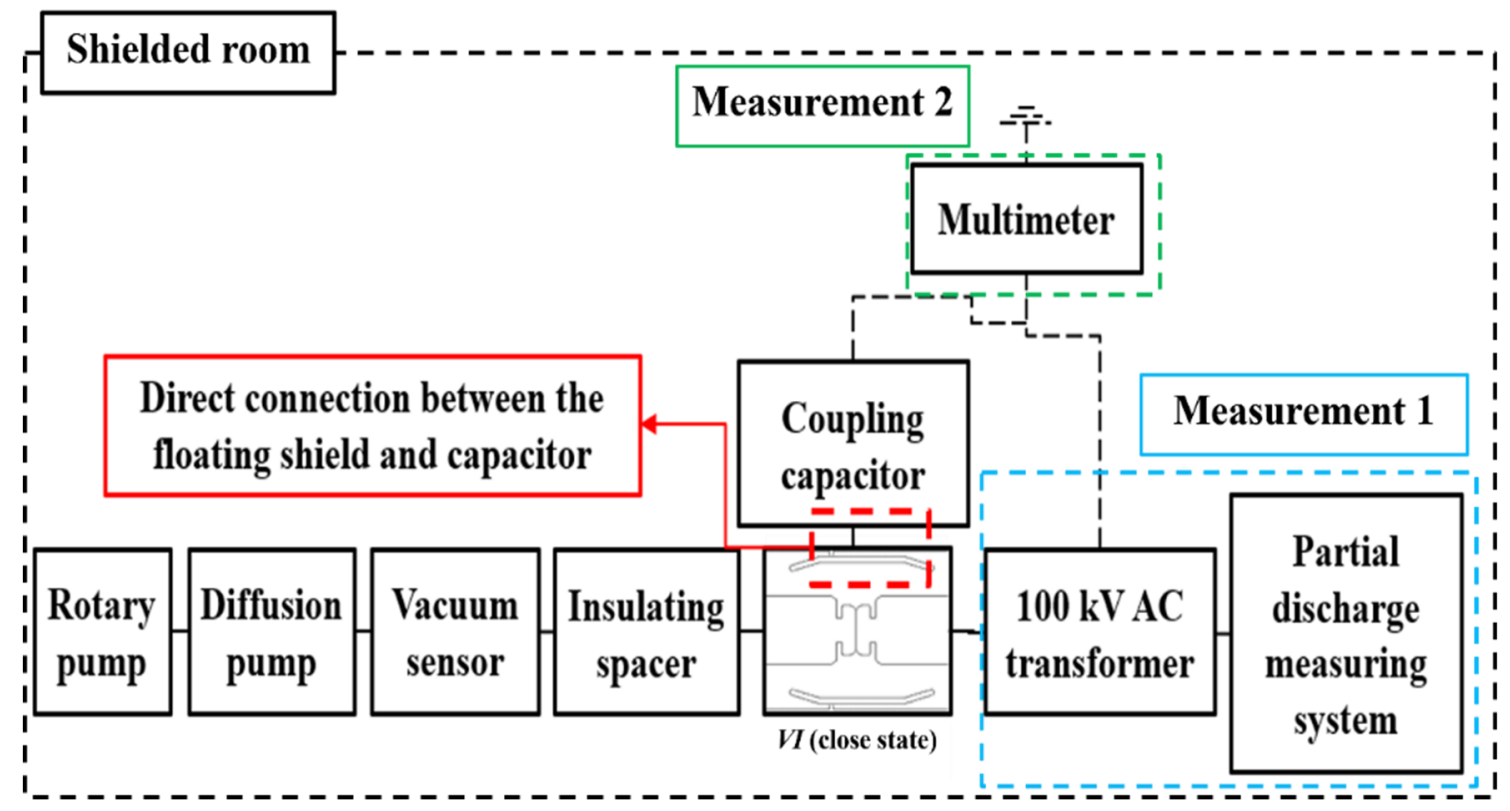

Figure 10. Schematic drawing of the partial discharge experiment of VI according to the vacuum degree.

The partial discharge and induced voltage experiments are conducted in a shielded room. As with the dielectric experiment, a combination of a rotary pump and a diffusion pump was used to deposit and control the vacuum degree, and a vacuum sensor was used to check the vacuum degree of the VI. Also, an insulating spacer was installed to impart electrical stability between the vacuum sensor and the VI and the AC transformer with a capacity of $100 \mathrm{kV}$ (with a cut-off current of $50 \mathrm{~mA}$ ). The partial discharge measurement system uses LDS-6 of Doble Lemke Co.Ltd. based in Germany; the measurement method of LDS-6 was in accordance with IEC 60270, and Phase Resolved Partial Discharge (PRPD) method was applied. The VI was in the closed state, and the coupling capacitor was directly connected to the floating shield. An input voltage was applied to the moving contact of the VI, and it was grounded at the end of the coupling capacitor. At that point, a multimeter with a capacity of $100 \mathrm{kHz}$ and an AC accuracy of $0.025 \%$ was installed to measure the 
induced voltage between the coupling capacitor and the ground. The advantage of this experimental circuit and method is that it can simulate the normal operation condition of VI, and the electrical influence between the contact and the floating shield can be more accurately identified. Figure 11 shows the experimental method for the partial discharge and induced voltage.

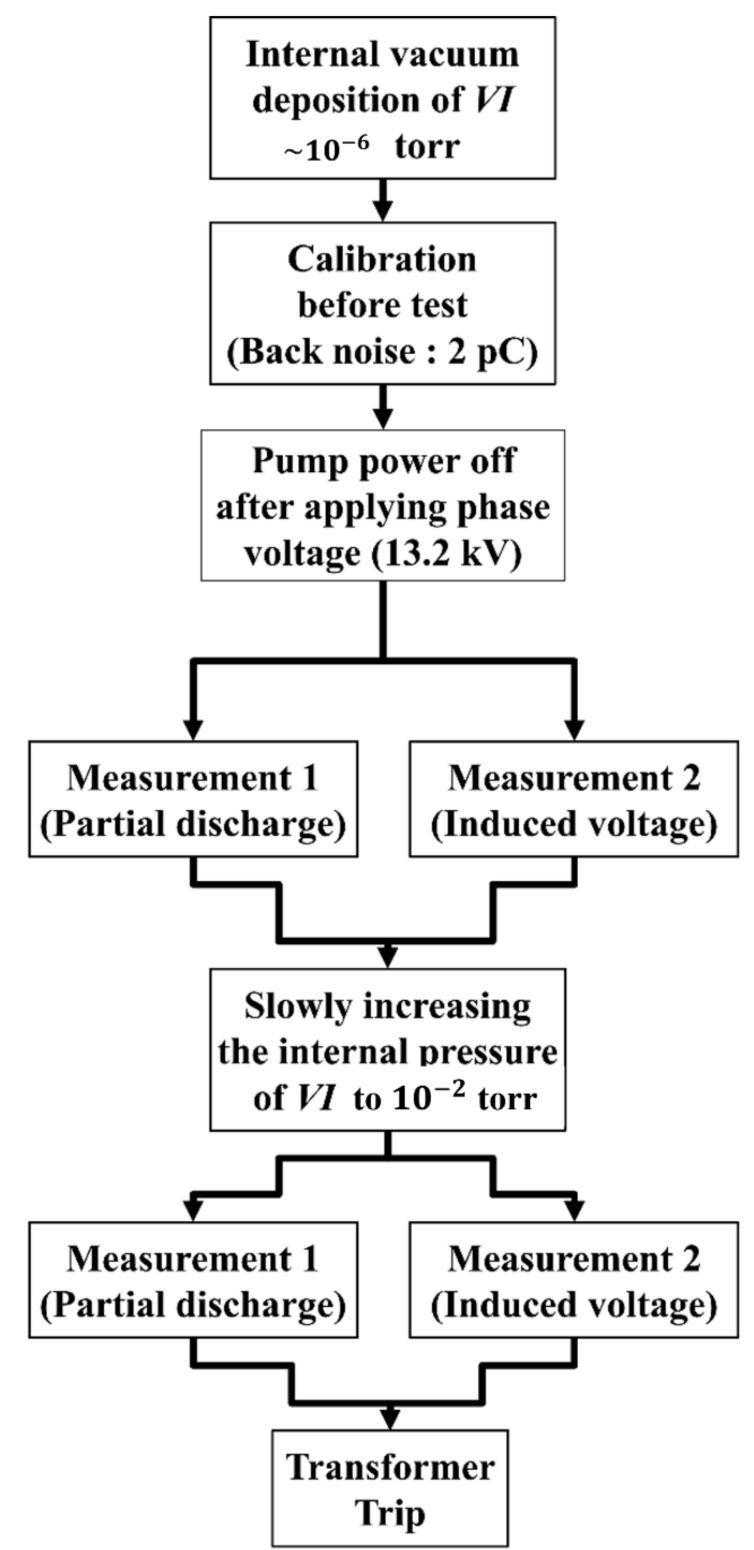

Figure 11. Experimental method for the partial discharge experiment.

As shown in Figure 11, the vacuum degree of the VI was increased up to $10^{-6}$ torr. The calibration of the partial discharge measuring system was performed before the experiment, and back noise was set to $2 \mathrm{pC}$. In addition, an AC voltage of $13.2 \mathrm{kV}$ with a frequency of $60 \mathrm{~Hz}$ was continuously applied because the phase voltage of $22.9 \mathrm{kV}$, the distribution class voltage in the Republic of Korea, is $13.2 \mathrm{kV}$. While gradually increasing the internal pressure of the VI to $10^{-2}$ torr, the partial discharge and induced voltage according to the vacuum degree were measured. A total of five VIs were used in the experiment, and a total of ten experiments were conducted for each VI. The partial discharge experiment was conducted for $145 \mathrm{~m}$ while the vacuum degree was maintained, and the partial discharge and induced voltage for each experiment were compared. 
Figure 12 shows the partial discharge and induced voltage characteristics according to the vacuum degree. The partial discharge and induced voltage did not occur in the high vacuum range of $10^{-6}$ to $10^{-4}$ torr but did at $10^{-3}$ and $10^{-2}$ torr, respectively. Subsequently, the flashover between the contact and the floating shield occurred at $10^{-2}$ torr, and the $\mathrm{AC}$ transformer was tripped. Figure 13 shows the phase-charge plot according to the vacuum degree of VI.
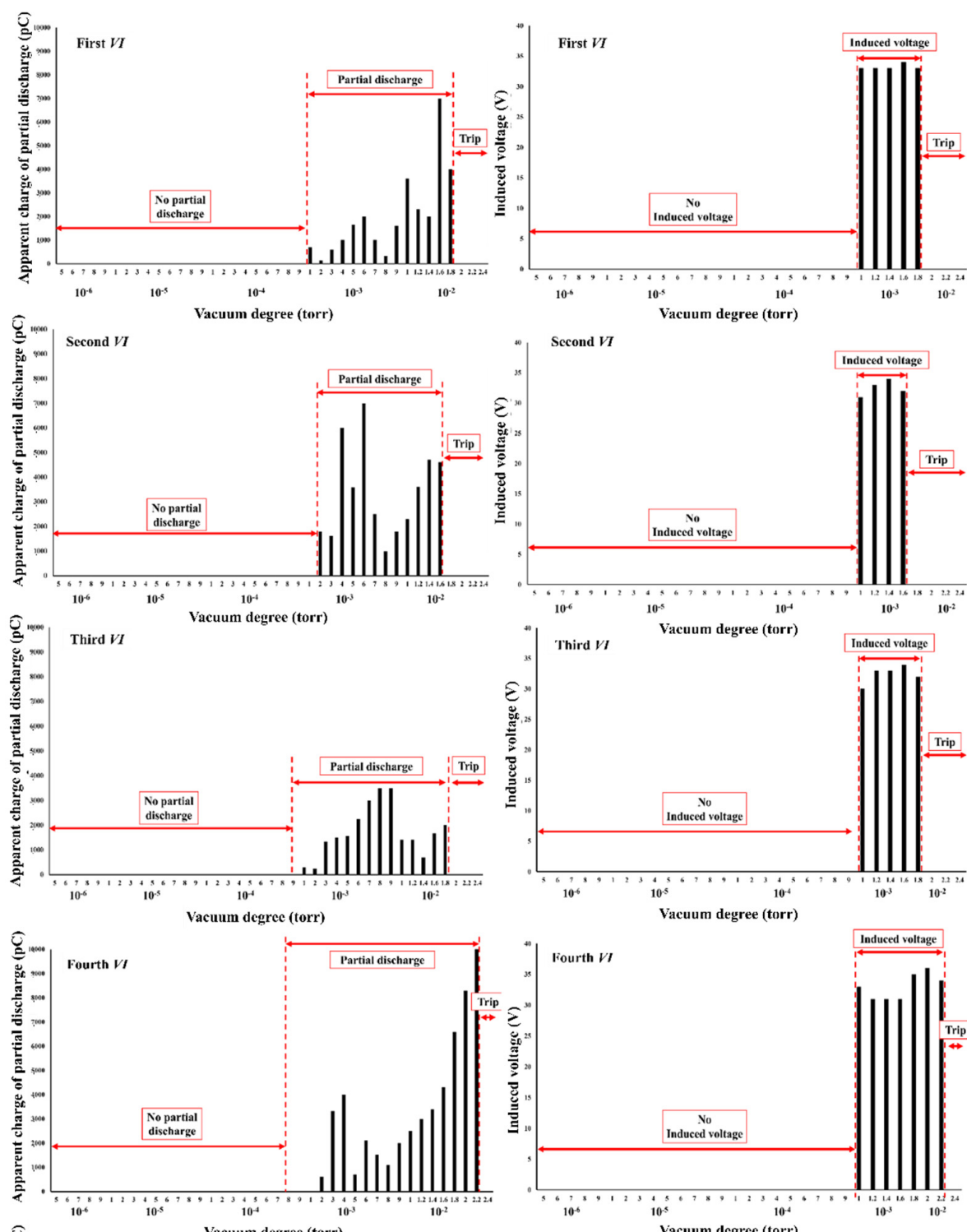

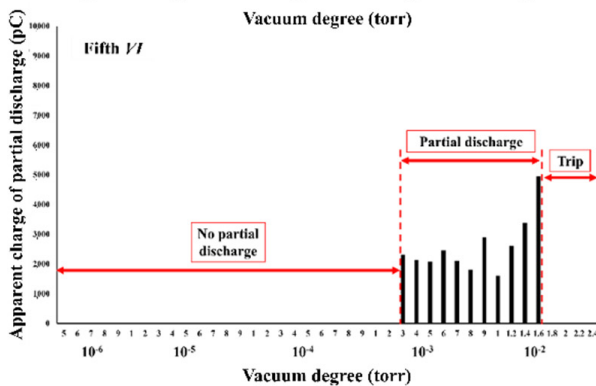

(a)

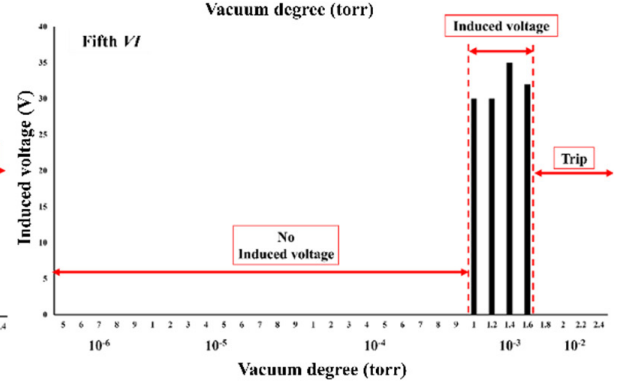

(b)

Figure 12. Partial discharge and induced voltage characteristics according to the vacuum degree. (a) Partial discharge, (b) Induced voltage. 


\section{$10^{-5}$}

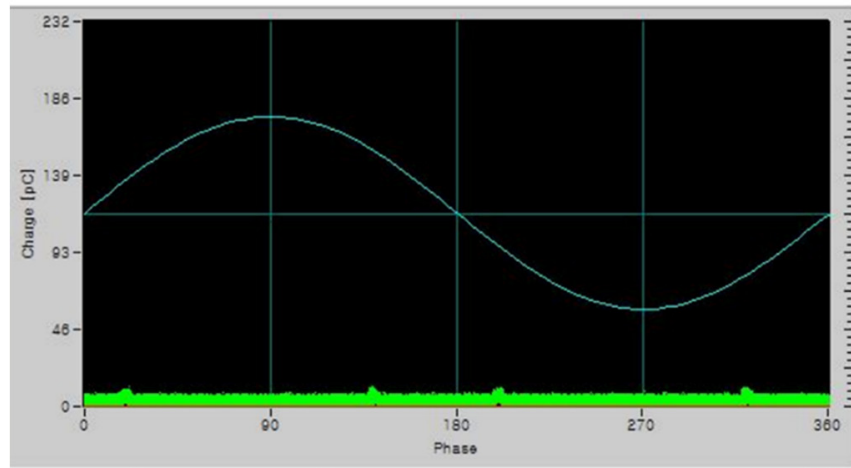

$10^{-3}$

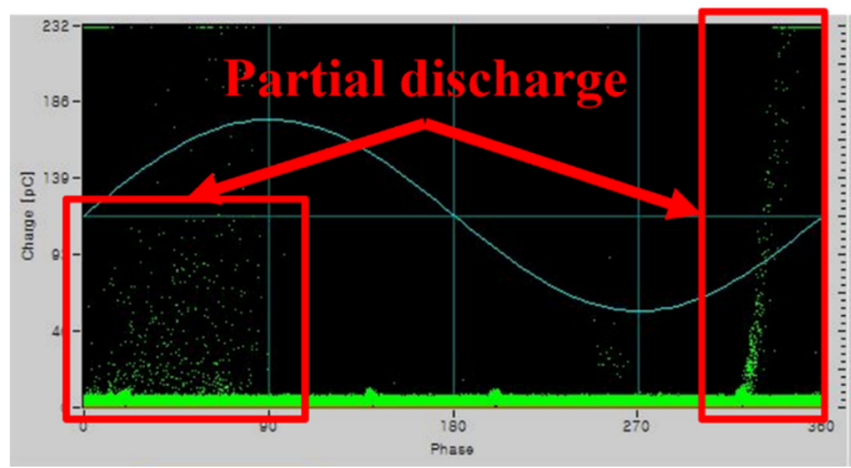

$10^{-4}$

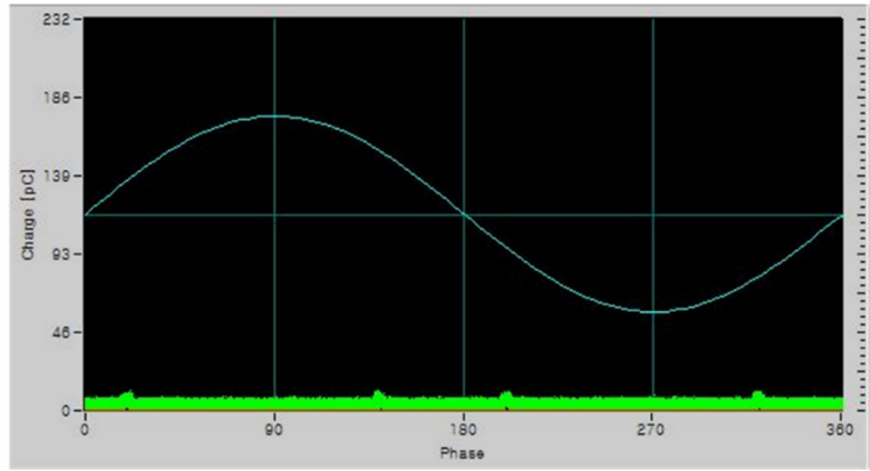

$10^{-2}$

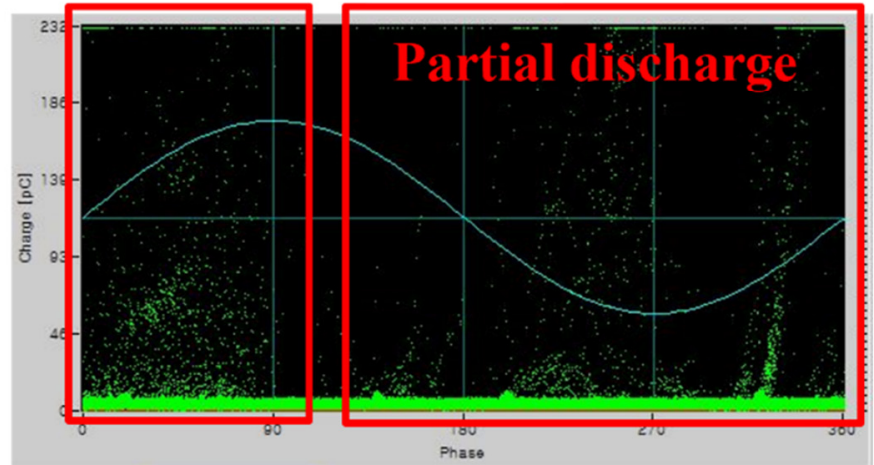

Figure 13. Phase-charge plot according to the vacuum degree of VI.

As shown in Figure 13, a partial discharge between the contact and the floating shield was generated from $10^{-3}$ torr. In addition, it was confirmed that as the internal pressure of VI increased, more apparent charges were distributed. Table 2 shows the peak and minimum apparent charge and induced voltage values for each experiment. As shown in Table 2, the pattern and apparent charge differed for VIs with the same mechanical structure and electrical characteristics. However, the induced voltage was constant at a magnitude of about 30 35 V. Therefore, to monitor the vacuum degree of the VI, it is essential to continuously check the minimum apparent charge and duration, not the maximum apparent charge of the partial discharge, along with the induced voltage of a certain magnitude.

Table 2. Peak and minimum apparent charge and induced voltage for each experiment.

\begin{tabular}{|c|c|c|c|c|c|}
\hline Measures No. & First & Second & Third & Fourth & Fifth \\
\hline Peak value (pC) & 7000 & 7000 & 3500 & 10,000 & 4944 \\
\hline Minimum value ( $\mathrm{pC}$ ) & 136 & 1000 & 250 & 605 & 1600 \\
\hline Induced voltage (V) & & & $30 \sim 35$ & & \\
\hline
\end{tabular}

Figure 14 shows the maintenance of VI. The apparent charge was set at about $130 \mathrm{pC}$ for real-time monitoring of the vacuum degree in the VI. Additionally, the duration was set within about $3 \mathrm{~m}$, which is $1 / 10$ of the $35 \mathrm{~min}$ duration after reaching the range of $1 \sim 3 \times 10^{-3}$ torr because the dielectric strength of the vacuum degree rapidly decreased at $10^{-3}$ torr. 


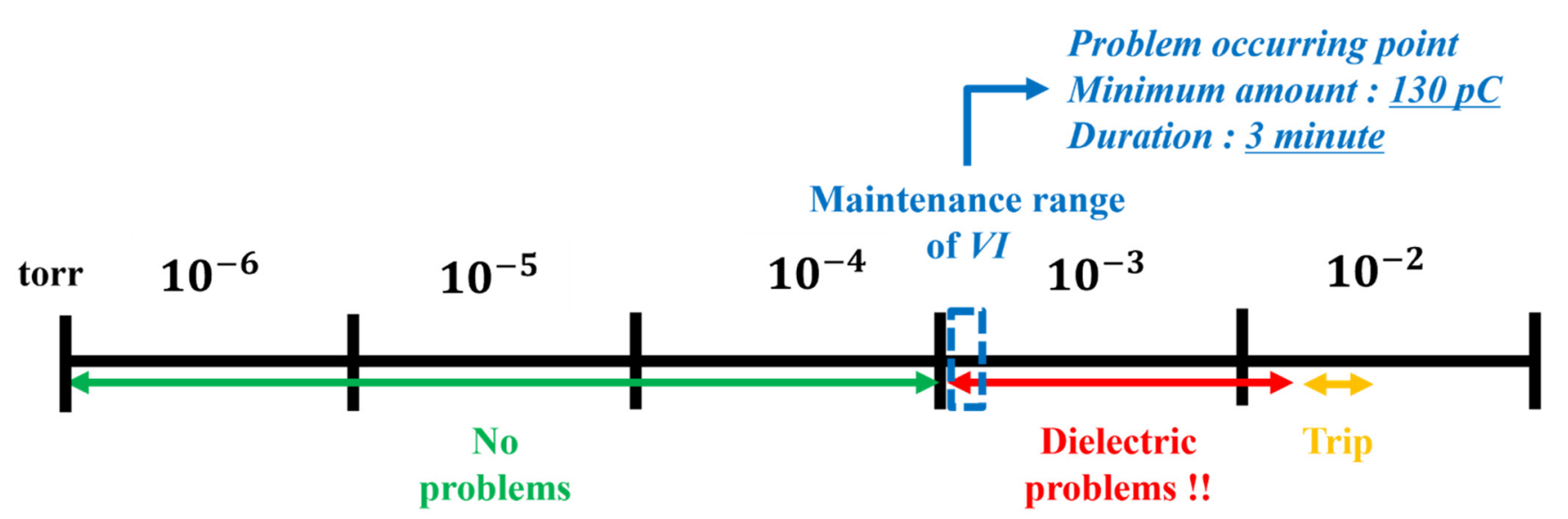

Figure 14. Maintenance of the VI.

\section{Insulation Supplement Design Method for the Real-Time Monitoring Technology}

Distribution class high-voltage apparatus are mainly made of a solid insulating material such as epoxy resin, and a VI is installed inside the housing of the solid insulation high-voltage apparatus. For high reliability and efficiency, the research and development into real-time monitoring technologies of a VI that can be installed inside the housing are ongoing. However, real-time monitoring technologies cause electrical accidents in high-voltage apparatus. Figure 15 shows the dielectric problems that can occur when real-time monitoring is applied. A high electric field was generated at the connection between the floating shield and the coupling capacitor. Accordingly, the interface discharge between the moving contact and the fixed contact occurred in the open state of the VI and from the contact to the coupling capacitor in the close state.

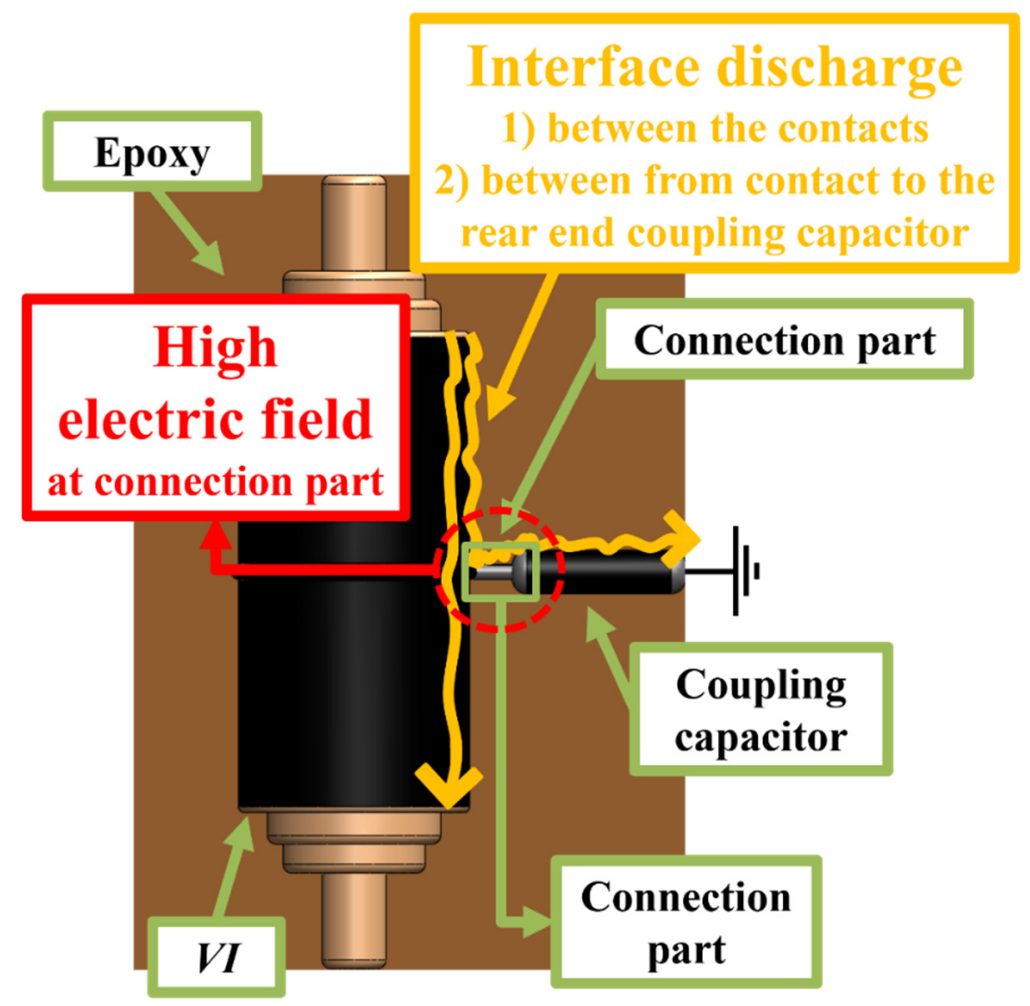

Figure 15. Dielectric problems when real-time monitoring technology is applied.

To prevent the dielectric problems associated with the real-time monitoring technology, it is essential to suppress the concentration of the high electric field at the connection part 
between the floating shield and the coupling capacitor. The insulation supplement design of the real-time monitoring technology was performed with COMSOL Multiphysics, which can calculate the electric field on 3D models using the FEM. Figure 16 shows the insulation supplement design factor and base model. The shield was installed in the housing of solid insulation high-voltage apparatus because of the ease of manufacturing the housing and the improvement of the insulation performance. Therefore, in this paper, it was adopted for the shield method in the insulation supplement design for the real-time monitoring technology.

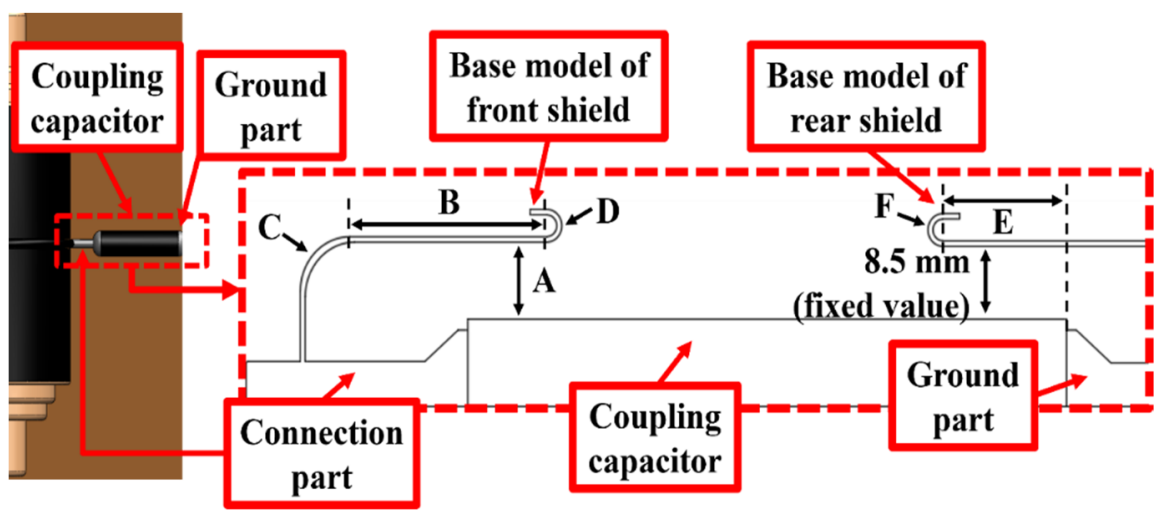

Figure 16. Insulation supplement design factor and initial model.

In Figure 16, A refers to the distance between the coupling capacitor and the front shield, B refers to the width of the front shield, C refers to the rounding of the front shield, $D$ refers to the curvature of the front shield, E refers to the width of the rear shield, and $F$ refers to the curvature of the rear shield. The distance between the coupling capacitor and the rear shield was fixed at $8.5 \mathrm{~mm}$ to reduce structural problems such as cracking of the epoxy resin due to heat shrinkage in low temperatures. Moreover, an interface criterion electric field of $2.2 \mathrm{kV} / \mathrm{mm}$ [19] and an AC particle discharge inception electric field of $2.1 \mathrm{kV} / \mathrm{mm}$ were applied. Table 3 shows the parameters for the FEM. The VI was in the open state, and the voltage applied to the moving contact was $125 \mathrm{kV}$ which is the Basic Impulse Insulation Level (BIL) of the distribution class in accordance with IEC 62271-1. The fixed contact and the rear end of the coupling capacitor were grounded. Moreover, the floating shield and front end of the coupling capacitor were in floating condition.

Table 3. Parameter for the FEM.

\begin{tabular}{cc}
\hline Materials & Relative Permittivity \\
\hline Vacuum & 1 \\
Contact, floating shield, and connection part (conductor) & 1 \\
Epoxy resin & 3.5 \\
Chamber (ceramic) & 9.8 \\
Coupling capacitor (ceramic) & 9.9 \\
Cover of VI and coupling capacitor (silicone) & 12 \\
\hline
\end{tabular}

Figure 17 shows the electrical characteristics of the front and rear shields. Six types of factors are sequentially adopted for the insulation supplement design of the front and rear shields. Table 4 shows the design factors of the front and rear shields that were adopted. Based on these factors, the front and rear shields were designed, as shown in Figure 18. Table 5 shows the electrical characteristics of the final model. As shown in Table 5, SF is adopted to check the electrical stability. SF is given by the following Equation [20]:

$$
S F=\frac{E_{\text {Criterion }}}{E_{\text {Designed }}}
$$




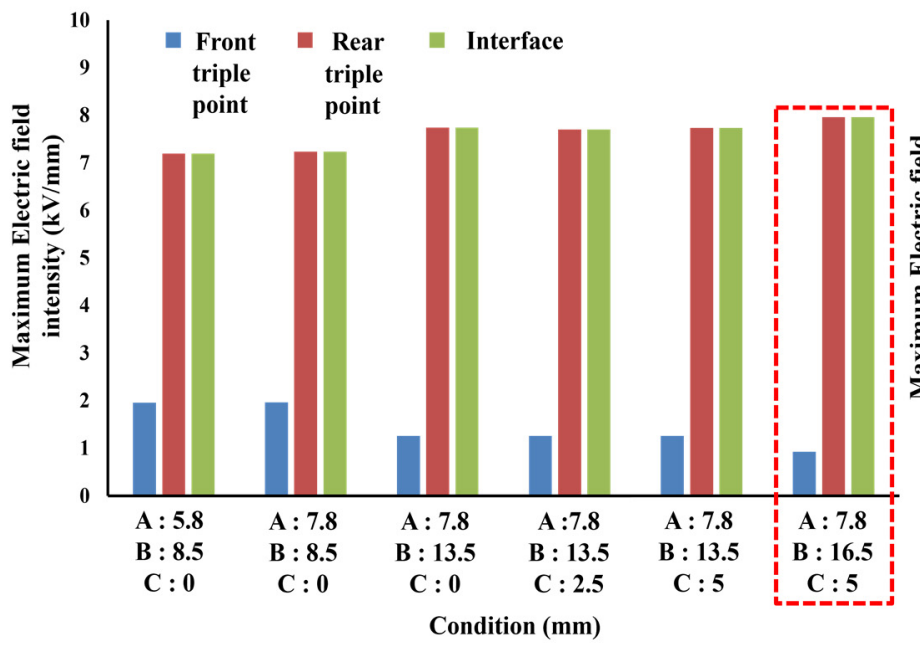

(a)

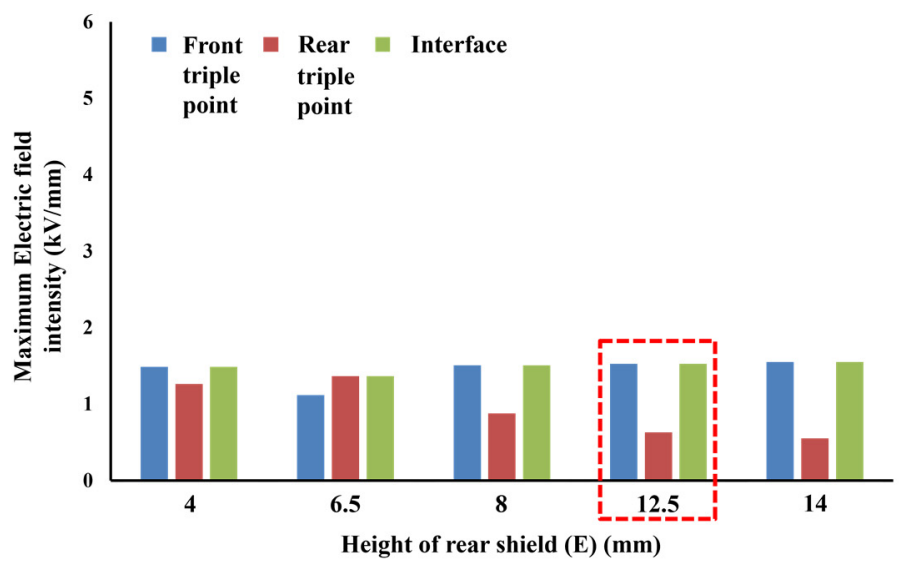

(c)

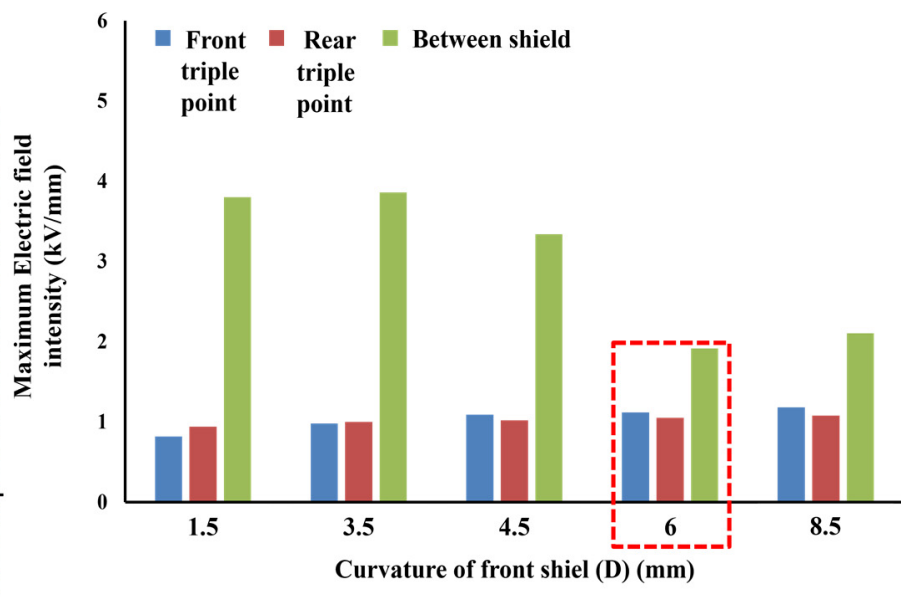

(b)

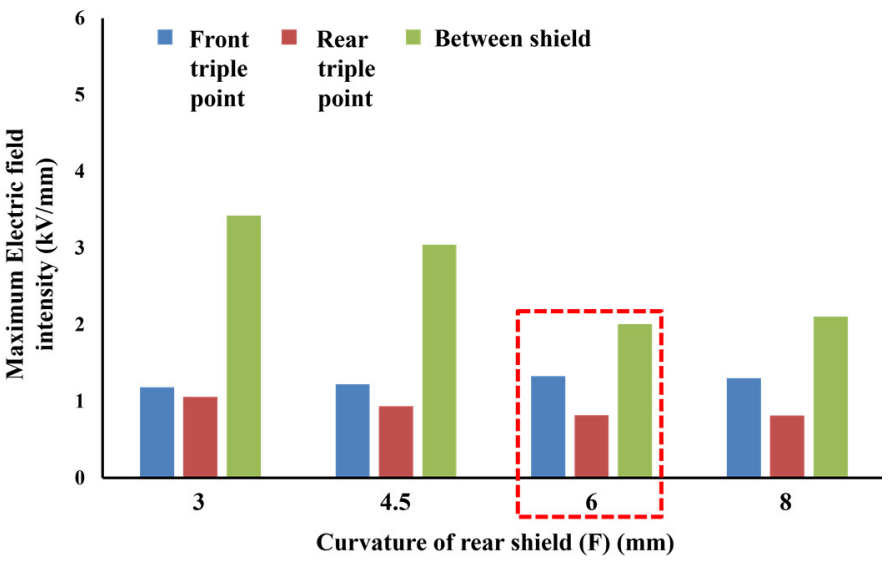

(d)

Figure 17. Electrical characteristics of front and rear shield according to design factors. (a) Factor A, B, and C; (b) Factor D; (c) Factor E; (d) Factor F.

Table 4. Design factors of the front and rear shields.

\begin{tabular}{cccccc}
\hline $\mathbf{A}$ & B & C & D & E & F \\
\hline $7.8 \mathrm{~mm}$ & $16.5 \mathrm{~mm}$ & $5 \mathrm{~mm}$ & $6 \mathrm{~mm}$ & $12.5 \mathrm{~mm}$ & $6 \mathrm{~mm}$ \\
\hline
\end{tabular}

Table 5. Electrical characteristics of the final model.

\begin{tabular}{ccccc}
\hline Component & Front Shield & Rear Shield & Interface \\
Measures & & 2.1 & & 2.2 \\
\hline$E_{\text {Criterion }}(\mathrm{kV} / \mathrm{mm})$ & 2.01 & 2.09 & 1.12 \\
\hline$E_{\text {Designed }}(\mathrm{kV} / \mathrm{mm})$ & 1.04 & 1.00 & 2.50 \\
\hline$S F$ & & &
\end{tabular}




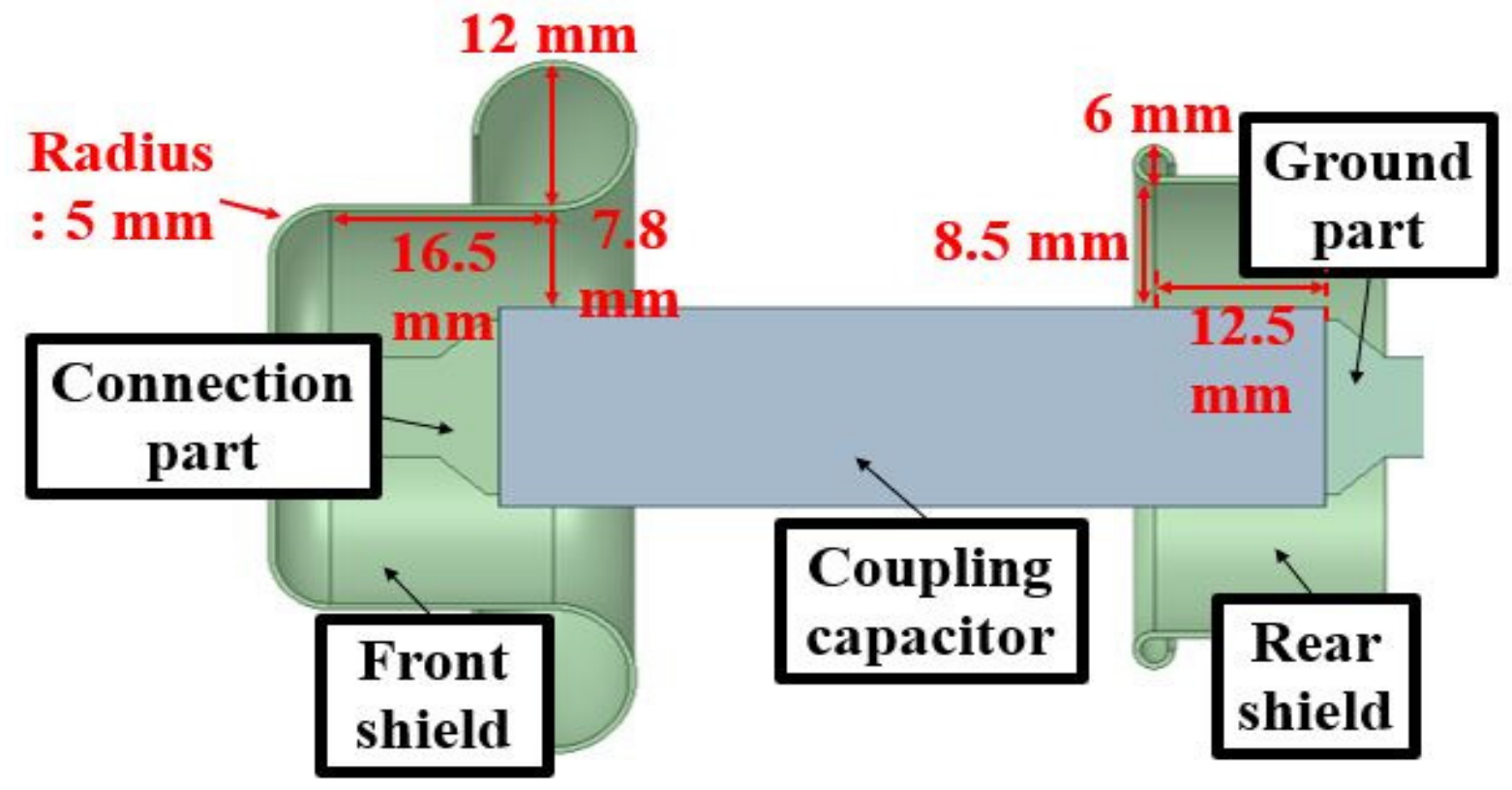

Figure 18. The final model of Insulation supplement design.

In Equation (4), $E_{\text {criterion }}$ refers to the maximum electric field at the discharge of the dielectric material, and $E_{\text {Designed }}$ refers to the maximum electric field of the designed model. If $S F$ is less than 1, the insulation performance is very unsafe [21]. Alternatively, if $S F$ is greater than 1, the performance is safe [21]. As a result, the electrical characteristics of the final model are all safe because the value of SF exceeds 1. Figure 19 shows the comparison of electric field intensity according to the shield. As shown in Figure 19, when the shield is not designed, the electric field intensity of the interface is $8.30 \mathrm{kV} / \mathrm{mm}$. However, when the shield is designed, the electric field intensity of the interface is $2.20 \mathrm{kV} / \mathrm{mm}$. Accordingly, the reduction ratio on the electric field intensity at the interface is $73.5 \%$. Therefore, it is found that high reliability can be obtained through the insulation supplement design method when real-time monitoring technology is installed in solid insulation highvoltage apparatus. 


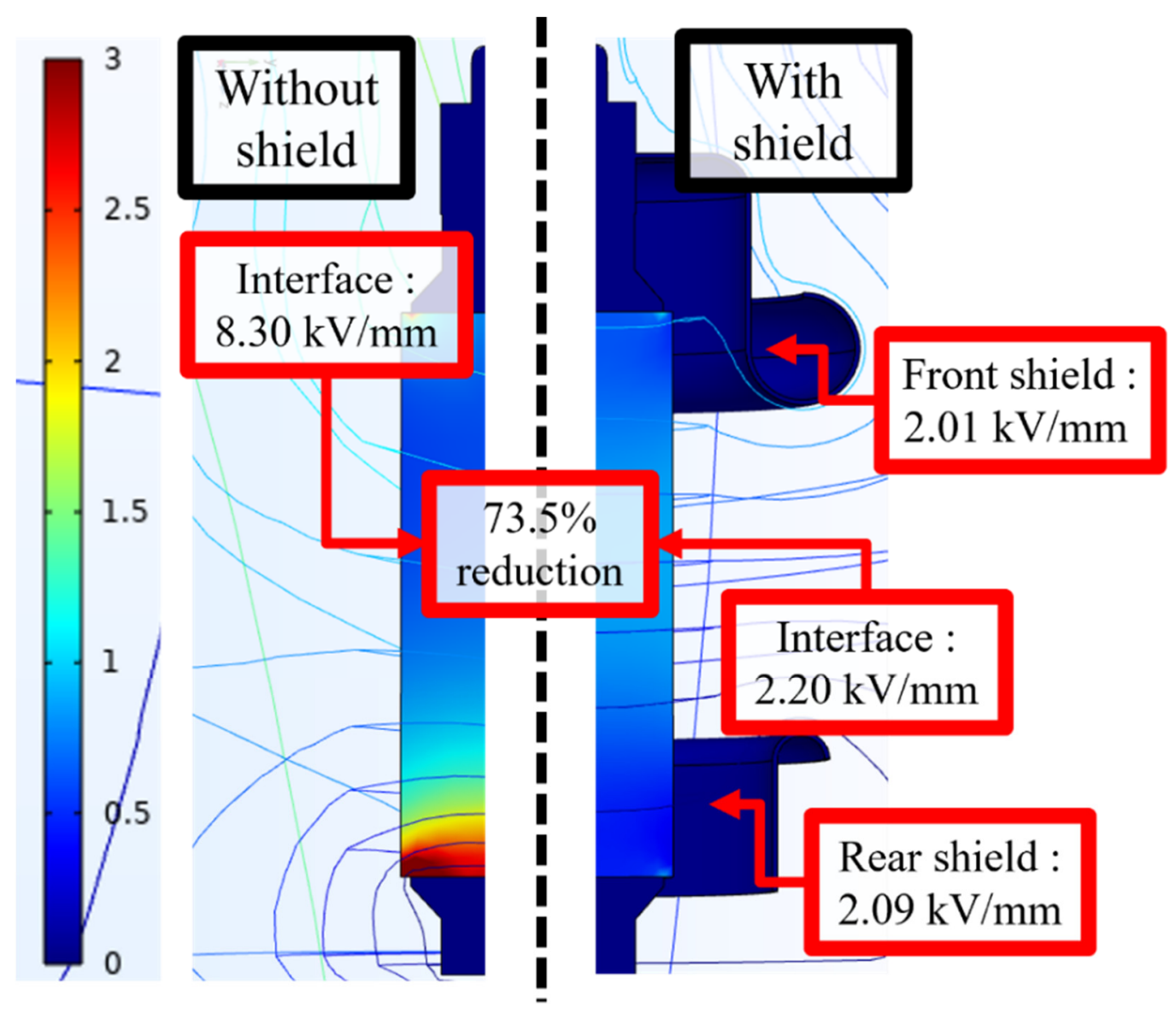

Figure 19. The final model of Insulation supplement design.

\section{Conclusions}

In this paper, a method for the real-time monitoring of the vacuum degree and an insulation supplement design for a distribution class vacuum interrupter were proposed. The results derived from this study can be summarized as follows:

- The dielectric strength of the vacuum rapidly decreased at $10^{-3}$ torr. To maintain high reliability and efficient maintenance, it is found that the VI should be replaced when the vacuum degree of the VI is $10^{-3}$ torr.

- The pattern and amount of partial discharge were different for each experiment, even for VIs with the same mechanical structure and electrical characteristics. The induced voltage was constant with a magnitude of about 30 35 V.

- To monitor the vacuum degree of the VI, it is important to continuously check the minimum amount of partial discharge and duration along with a certain magnitude of induced voltage rather than monitoring the peak amount of partial discharge.

- The electric field intensity generated at the interface of the coupling capacitor could be reduced by $73.5 \%$ through the insulation supplement design of the real-time monitoring technology.

- Solid insulation high-voltage apparatus to which real-time monitoring technology is applied can improve the reliability of power transmission and the efficiency of maintenance.

Author Contributions: Conceptualization, S.B.; investigation, H.-W.L. and S.B.; software, S.B.; writing-original draft, S.B.; supervision, B.-W.L.; writing—review and editing, B.-W.L. All authors have read and agreed to the published version of the manuscript.

Funding: This research received no external funding.

Institutional Review Board Statement: Not applicable. 
Informed Consent Statement: Not applicable.

Data Availability Statement: Not applicable.

Acknowledgments: This work was supported by the National Research Foundation of Korea (NRF) grant funded by the Republic of Korea government (MSIT) (No. 2021R1F1A104554711). This work was supported in part by the Korean Institute of Energy Technology Evaluation and Planning (KETEP) and in part by the Ministry of Trade, Industry, and Energy (MOTIE) of the Republic of Korea (No. 20179310100040).

Conflicts of Interest: The authors declare no conflict of interest.

\section{References}

1. Zhang, Y.; Zhou, Q.; Zhao, L.; Ma, Y.; Lv, Q.; Gao, P. Dynamic reactive power configuration of high penetration renewable energy grid based on transient stability probability assessment. In Proceedings of the 4th Conference on Energy Internet and Energy System Integration (EI2), Wuhan, China, 30 October-1 November 2020; pp. 3801-3805.

2. Lamnadi, M.; Trihi, M.; Boulezhar, A. Study of a hybrid renewable energy system for a rural school in Tagzirt, Morocco. In Proceedings of the 2016 International Renewable and Sustainable Energy Conference (IRSEC 2016), Marrakech, Morocco, 14-17 November 2016.

3. Harrouz, A.; Belatrachem, D.; Boulal, K.; Colak, I.; Kayisli, K. Social acceptance of renewable energy dedicated to electric production. In Proceedings of the 2020 9th International Conference on Renewable Energy Research and Application (ICRERA), Glasgow, UK, 27-30 September 2020; pp. 283-288.

4. Guzhov, S.; Krolin, A. Use of big data technologies for the implementation of energy-saving measures and renewable energy sources in buildings. In Proceedings of the 2018 Renewable Energies, Power Systems \& Green Inclusive Economy (REPS-GIE), Casablanca, Morocco, 23-24 April 2019; pp. 1-5.

5. Schellekens, H.; Devismes, M.F.; Nicolle, C. Vacuum interrupters: Design optimisation requires reliable experimental data. In Proceedings of the 2011 1st International Conference on Electric Power Equipment-Switching Technology, Xi'an, China, 23-27 October 2011; pp. 56-59.

6. Yokomichi, S.; Kozako, M.; Hikita, M.; Sato, K.; Moriyama, T.; Urai, H.; Nakaoka, T.; Tsuchiya, K. Development of Diagnostic Methods for Vacuum Leakage from Vacuum Interrupter by Partial Discharge Detection. In Proceedings of the 2016 27th International Symposium on Discharges and Electrical Insulation in Vacuum (ISDEIV), Suzhou, China, 18-23 September 2016; Volume 2, pp. 1-4.

7. Mei, Y.; Yuan, H.; Wang, X.; Sha, K.; Wang, P.; Guo, J.; Xu, W.; Rong, M.; Wang, W. Study on the change tendency of electromagnetic signal under different vacuum degree for $10 \mathrm{kV}$ vacuum chamber. In Proceedings of the TENCON 2015-2015 IEEE Region 10 Conference, Macao, China, 1-4 November 2015; pp. 1-6.

8. Duan, X.; Li, F.; Dong, E.; Liao, M.; Guo, Y.; Zou, J. Study on inner vacuum pressure measurement system of vacuum circuit breakers. In Proceedings of the 2017 4th International Conference on Electric Power Equipment-Switching Technology (ICEPE-ST), Xi'an, China, 22-25 October 2017; pp. 880-884.

9. Nakano, Y.; Kozako, M.; Hikita, M.; Tanaka, T.; Kobayashi, M. Estimation of Internal Pressure of Vacuum Interrupter by Measuring Partial Discharge Current. In Proceedings of the 28th International Symposium on Discharges and Electrical Insulation in Vacuum (ISDEIV), Greifswald, Germany, 23-28 September 2018; pp. 611-614.

10. Abe, J.; Tanabe, T.; Yano, T.; Yoshida, S.; Inoue, N. The Electric Discharge Detection Method in the Low Vacuum Region of Vacuum Interrupter. Electron. Commun. Jpn. 2016, 100, 59-66. [CrossRef]

11. Deng, X.; Li, W.; Liu, B. Discharge Properties and Diagnosis of Gas Pressure in Vacuum Interrupter. In Proceedings of the 2011 IEEE Power Engineering and Automation Conference, Wuhan, China, 8-9 September 2011; pp. 314-317.

12. Saito, H.; Matsui, Y.; Sakaki, M. Discharge Properties in Low Vacuum and Vacuum Monitoring Method for Vacuum Circuit Breakers. In Proceedings of the 2006 International Symposium on Discharges and Electrical Insulation in Vacuum (ISDEIV'06), Matsue, Japan, 25-29 September 2006; pp. 181-184.

13. Kamarol, M.; Ohtsuka, S.; Hikita, M.; Saitou, H.; Sakaki, M. Determination of gas pressure in vacuum interrupter based on partial discharge. IEEE Trans. Dielectr. Electr. Insul. 2007, 14, 593-599. [CrossRef]

14. Zhang, K.; Kuo, L.; Sun, Y. Study on the Relationship between Partial Discharge and Vacuum Degree in Arc Extinguish Chamber. Mod. Electr. Power 2012, 4, 46-50.

15. Wang, C.; Shu, N. Research on Acoustic Monitor of Vacuum of Vacuum Breakers. J. Univ. Hydraul. Electr. Eng. Yichang 2003, 6, 512-515.

16. Youn, Y.W.; Hwang, D.H.; Sun, J.H.; Song, K.D.; Koh, H.; Kim, Y. Development of measuring and analysis method for monitoring the vacuum degree in VI. KIEE 2013, 2013, 1370-1371.

17. Zhang, X.; Liu, X.; Fan, X.; Huang, Z.; Fan, J.; Liang, C.; Shi, W. A high accurate sensor research and its application for VCB's internal pressure on-line condition monitor. In Proceedings of the 25th International Symposium on Discharges and Electrical Insulation in Vacuum (ISDEIV), Tomsk, Russia, 2-7 September 2012. 
18. Nakano, Y.; Kozako, M.; Hikita, M.; Tanaka, T.; Kobayashi, M. Estimation method of degraded vacuum in vacuum interrupter based on partial discharge measurement. IEEE Tran. Dielectr. Electr. Insul. 2019, 26, 1520-1526. [CrossRef]

19. Seunghee, O.; Eliana, B.; Ratri, D.; Park, Y.; Kang, H. A study on the creepage e discharge characteristics to design a stop joint box for a superconducting cable. KIEE 2021, 35, 42-47.

20. Hong, J.; Heo, J.I.; Nam, S.; Kang, H. Study on the Dielectric characteristics of gaseous, liquid, and solid insulation materials for a high voltage superconducting apparatus. IEEE Trans. Appl. Supercond. 2013, 23, 7700604. [CrossRef]

21. Bang, S.; Kim, H.S.; Koo, J.H.; Lee, B.W. Consideration of the insulation design method on a $\pm 200 \mathrm{kV}$ converter valve unit in an HVDC converter hall. Energies 2021, 14, 2296. [CrossRef] 